\title{
Beyond dead reckoning: Mobilities of return in the Pacific
}

\author{
John Taylor
}

\section{Abstract}

In recent decades, the term 'mobility' has emerged as a defining paradigm within the humanities. For scholars engaged in the multidisciplinary topics and perspectives now often embraced by the term Pacific Studies it has been a much more longstanding and persistent concern. Even so, specific questions regarding 'mobilities of return'-that is, the movement of people 'back' to places that are designated, however ambiguously or ambivalently, as 'home'-have tended to take a back seat within more recent discussions of mobility, transnationalism and migration. Situating return mobility as a starting point for social inquiry gives rise to important questions regarding the broader context and experience of human mobility, community and identity. This represents an important contribution to emerging perspectives that seek to move beyond binary optics of domestic or translocal versus international migration, local versus foreign identity, and indeed of stasis versus mobility itself. This introductory chapter foregrounds the ways in which the volume as a whole demonstrates the extent to which the prospect and practice of returning home, or of navigating returns between multiple homes, is a central rather than peripheral component of contemporary Pacific Islander mobilities and identities. 
From wild 19th-century theorising around the origins of Pacific settlement (see Howe 2003), Malinowski's pioneering study of kula exchange circuits (Malinowski 1961) and Hau'ofa's seminal revisioning of 'our sea of islands' (Hau'ofa 1994), the reality of life lived reciprocally within and across wide Oceanic expanses has ensured that questions of human movement have remained central to Pacific scholarship. Even so, and while by no means rendered invisible or irrelevant, specific questions relating to what we here refer to as 'mobilities of return'-that is, the movement of people 'back' to places that are designated, however ambiguously or ambivalently, as 'home'- have tended to take a back seat within more recent discussions of mobility, transnationalism and migration. As this book demonstrates, situating return mobility as a starting point for social inquiry, rather than a middle or end point, postscript or afterthought, gives rise to important questions regarding the broader context and experience of human mobility, community and identity. This, we argue, represents an important contribution to emerging perspectives that seek to move beyond binary optics of domestic or translocal versus international migration, local versus foreign identity, and indeed of stasis versus mobility itself (Glick Schiller and Salazar 2013; and for an excellent overview of Pacific scholarship, see Keck and Scheider 2015). More importantly still, the chapters collected here demonstrate the extent to which in the current 'age of migration' (Castles and Miller 2009) the prospect and practice of returning home, or of navigating returns between multiple homes, is a central rather than peripheral component of contemporary Pacific Islander mobilities and identities.

Oral-historical, linguistic and archaeological evidence shows that the earliest colonisers of the Pacific not only expertly navigated their way across vast ocean expanses as they sought out new lands. From the very beginnings of human settlement to the region people were also travelling 'the other way'. Across the Pacific, aiding rather than hindering voyages of discovery, the prevailing south-easterly trade winds helped to ensure a fast and safe return in the event of landfall not being made (Irwin 1992). In this way, in possession of diverse strategies including what later European navigators called 'dead reckoning', by which navigators attempted to ascertain their present position based on direction and distance travelled from a fixed point of departure, the promise and safety net of 'return mobility' formed an epistemological as well as practical basis for islandto-island colonisation and dwelling. Inevitably, as social and affective as well as practical networks of trade and kinship obligation emerged over 
the course of such journeys, the notion of returning to departure points, homelands, bases of refuge or other familiar locations inevitably became tied up in the everyday habitus of Pacific Islander experience and existence.

Borrowing the nautical concept of dead reckoning here, taking account of the social, economic and political implications of dead reckoning has also been central to scholarship on human return migration and mobility in the Pacific region and beyond. Importantly, these terms and what they represent have also become increasingly important within aid and development policy and discourse within the 21st century. Even so, terminological distinctions are often vague and limited in usefulness, with migration and mobility often taken to refer solely to movements from one place of residence to another (migration), rather than including other forms of mobility, such as tourism or visits to friends and family, itinerant trading, travel for education or to access goods and services, or to perform unpaid domestic work (for an in-depth discussion of migration and mobility in international development policy, see Willis 2010). Where the Pacific is concerned, however, touted by a recent World Bank Pacific Possible, Labour Mobility report as 'the ten billion dollar prize' (Curtain et al. 2016), questions and issues around labour mobility are rapidly coming to the fore, especially in relation to seasonal labour schemes in New Zealand and Australia.

As discussed by Howard and Rensel, and Lee (both this volume), and reviewed by Gmelch (1980), scholarship up and into the 1980s tended to emphasise returns to homelands on simple binary terms both spatially and conceptually, especially in terms of reflecting either failure or success in meeting economic goals of migration. Reflecting and refracting these analytic trends, from the mid-1980s the highly influential MIRAB model likewise emphasised the central importance of migration (MI) and remittances $(\mathrm{R})$ alongside foreign aid $(\mathrm{A})$ and the bureaucratic public sectors (B) to the functioning of Pacific Island states (Bertram and Watters 1985; and for a more recent discussion Bertram 1999).

Highly structural, political-economic and governance-oriented perspectives such as these clearly failed to take into account the sociocultural, ideational or affective dimensions of migration. These aspects have come to the fore in more recent scholarship, particularly within anthropology, sociology, human geography and related disciplines (see especially Sheller and Urry 2006; Urry 2007; for the Pacific, Ward 1997; D'Arcy 2006; Lee and Francis 2009; Keck and Schieder 2015). 
Cathy Small's groundbreaking book, Voyages: From Tongan Villages to American Suburbs (2011), presented an highly intimate description and subtle analysis of Tongan diasporic mobilities and connections traced through in-depth fieldwork over some 15 years. Leulu Felise Va's's Saili Matagi: Samoan Migrants in Australia (2001) and Cluny Macpherson's pioneering work on Samoan migration, which has included asking important questions around the possibilities of homecoming within diasporic populations $(1985,1994,1999,2004)$, also represent important early contributions (and for a more recent important example focusing on American Samoa, see Van der Ryn 2012). Such issues have also been central points of concern within historical evaluations and re-evaluations around topics also defined by human mobility. This includes most notably the periods of early European exploration and cross-cultural encounter in the Pacific (e.g. Thomas 2009; Jolly et al. 2009), and more especially the contexts of Christian missionisation and the labour trade (Shineberg 1999; Sivasundaram 2005; Banivanua-Mar 2007). While rarely forming an explicit focus of interest, such works are replete with stories of Pacific Islander mobility, both across the Pacific and beyond, and often back again. In one particularly telling example, focusing on the theme of return across multiple generations, the documentary film Sugar Slaves: The Secret History of Australia's Slave Trade (Graham 1995) follows the story of Joe and Monica Leo, South Sea Islander descendants of Queensland plantation workers, recruited during the labour trade from Pentecost Island, Vanuatu (also see Taylor 2008). Undertaking a journey to recover a portion of their stolen past, the Leo's 'return' to Pentecost is fraught with the kind of emotionally unsettling ambivalence that also permeates many of the chapters in this volume.

Of particular importance to coming to grips with the profound complexities of return mobility have been studies focusing on the experience of children, adoption and the children of migrants (see Lee, this volume). As Yngvesson and Coutin (2006) have demonstrated in their comparison of US deportees to El Salvador and the 'roots trips' of Swedish transnational adoptees, for example, the return journeys of longterm migrants especially are often jarringly unsettling, if not dismantling of the mythologies of home and identity that configure them. Likewise, since Epeli Hau'ofa's cogent postcolonial critique of the hegemonic Western stereotypes that are so often bound up in models such as MIRAB (Hau'ofa 1994), scholars have struggled to take into account the high degree to which Pacific Islander diasporic practices also entail a profound 
disruption of easy notions of home and away, and with it the idea of 'return', even as these concepts retain vital practical and even embodied value. Just as Jolly (2001), inspired by Hau'ofa's vision, demonstrates the need to account for the copresence of values of 'roots' and 'routes', or stasis and mobility, in Pacific epistemologies and discourses, what is demonstrated time and again across these chapters is the necessity of understanding how meanings of values of home and away, as well as departure and return, are produced and transformed dialectically through context and time.

Dislodging the Western stereotypical location of Pacific 'Islander' homesfrom static, tiny island to the fluid sea-Hau'ofa persuasively argued that Pacific Islanders have always been on the move, and in doing so have always made and remade homes in multiple locations. His broad vision took in a vast global circulation of people and material goods, including in 'seaports and airports throughout the central Pacific, where consignments of goods from homes abroad are unloaded as those of the homelands are loaded' (1994: 156). Similarly, refusing to accept stereotypes of 'home Islanders' gobbling up remittances 'like parasites on their relatives abroad' (1994: 157), Hau'ofa instead highlighted the ethos of reciprocity that lies 'at the core of all oceanic cultures' and, as he put it:

the fact that for everything homeland relatives receive, they reciprocate with goods they themselves produce, by maintaining ancestral roots and lands for everyone, homes with warmed hearths for travelers to return to permanently or to strengthen their bonds, their souls, and their identities before they move on again (Hau'ofa 1994: 157).

Each of the chapters presented here focuses on the contemporary experiences that accompany such homecomings, as well as the shifting meanings and values of home that occur within the context of diaspora over time. While recognising and respecting that Hau'ofa's vision of the Pacific as a 'boundless sea of possibilities' (D'Arcy 2006: 7) presents an important ideological countermeasure to past and present colonial and neocolonial thinking, in this volume we are witness to a broad range of life predicaments, and personal and collective responses to these. Home, homecoming and relationships with homeland relatives are in some instances experienced positively as unproblematic and fundamentally life affirming, working to strengthen bonds of identity and community. More often, however, the individual contributions of this volume reveal the ambiguities and ambivalences that so often arise within the shifting 
contexts of human movement, migration and return mobility. Central to all analyses, however, is a strong sense of the individual and collective agency that is felt and exerted in such contexts. So too is the profoundly affective nature of experience relating to return migration and mobility, including the often unsettling mixtures of longing and anticipation, disappointment and danger, and happiness, hope and security that are all linked to the meanings and embodied practice of returning home.

The following chapter, by Wolfgang Kempf, explores 'diversification of return' as experienced by diasporic Banaba Islanders and their descendants. As Kempf outlines in nuanced detail, colonial and more recent histories of migration and mobility among Banabans is uniquely complex. The underpinnings of the present predicament began following the Second World War with the large-scale, involuntary collective resettlement of Banaba Islanders to Rabi, Fiji, and the subsequent carving out of Kiribati and Fiji as nation-states in the 1970s. As a result of these events, and while continuing to elevate the grounded identity of 'home island' over that of 'home nation', diasporic Banabans have not only developed an ambivalent and plural understanding of home and homeland, but also as a consequence of what (and where) it means to 'return' home. Presenting a cogent critique of methodological nationalism, Kempf provides a valuable terminological and analytic framework through which to conceptualise and understand the complex sequencing of displacement, resettlement, international migration and formation of transnational ties that may occur in diasporic settings everywhere. Kempf begins by noting the important distinction between 'return migration' on the one hand, and shorter 'return visits' on the other. From this basis, he offers three conceptual terms, all of which contribute to an overall understanding of the 'diversification of return': 'differentiation', 'reversal' and 'ramification'. First, and highlighting the distinction between homeland and nationstate, 'differentiation' acknowledges that assignations of home may differ significantly across contexts and through time. Secondly, noting the ways in which many Banabans have come to prioritise Rabi over Banaba as their home island and place of return, 'reversal' refers to the way in which directional reference points may shift along with the differentiation of homelands. Finally, recognising that the majority of those who do 'return' to Kiribati tend to resettle on the nation's main atoll of Tarawa, rather than Banaba itself, 'ramification' refers to the observation that this proliferation of homelands also entails directional perspectives on return mobility. 
In addition to the fine-grained detail he provides with regards to Banaba Islanders, this framework is particularly valuable to analysing contextual shifts in engagement of migrants with homelands everywhere.

The third chapter, by Howard and Rensel, similarly focuses on the migratory context of a specific island population, many of whom have also resettled in Fiji, along with making new homes in other international locations. Their chapter deftly analyses qualitative and quantitative research data spaning over 50 years to examine the complexly networked rather than purely dyadic ties to place that are formed across diasporic settings. As they demonstrate, the case of Rotuma is somewhat unusual for the overwhelmingly positive image of home and appraisals of homecoming journeys that are held by Rotumans. Even so, in doing so they highlight a key theme across all the chapters, that of the emotional or affective importance of home within the context of return mobility. Here, the value and expectation for Rotumans abroad to 'keep their relationships warm' demonstrates how rights to land form an important factor in defining mobility and settlement patterns, and how the emotional physicality of place and community remain entangled despite the distances of migration.

Compared to the overwhelmingly positive Rotuman experience of return migration and home visits, the predicament of Tongan youth described by Helen Lee is much more mixed. Applying classic anthropological theories of 'rites of passage', Lee examines the fraught experiences of Tongan youth who are sent home to learn their culture, and in doing so become 'truly Tongan'. Reflecting Kempf's concept of 'reversal', many of the youth in Lee's study are in fact returning home for the first time, and as such have very little knowledge of the Tongan cultural context they are stepping into. Ambiguously if not contradictorily situated 'betwixt and between' the categories 'stranger' and 'at home', and often racially designated as pälangi (foreign/white) these young people often experience harsh physical punishment alongside elements of Tongan traditional culture (anga fakatonga), which are together incorporated by local leaders and family members into disciplinary practices aimed at 'straightening them out'. Importantly, given the sometimes criminal or antisocial backgrounds of the young returnees, in this way Lee's study underscores the need to seriously examine the perspectives and experiences of the broader society that receives returnees, including here for example the sense of burden and potential risks that may accompany their arrival and presence. Even so, in 
her analysis of what for many is a journey into identity and acceptance, Lee also emphasises the importance of recognising the more positive and redemptive elements of homecoming.

Also focusing on the predicaments of youth in migration, Rachana Agarwal's chapter examines the social negotiation of agency and selfhood among young Palauan returnees. Centring especially on young women, this example emphasises the importance of gender to analyse return mobility. As she argues, while the young returnees she describes generally hold a stable and positive perception of home, the social experience of 'homecoming' is rarely smooth or seamless. A key reason for this is the disjuncture that exists between the social contexts across which such homecoming journeys are taken. In Palau, young people are expected to assume subordinate positions, including in terms of situations of age, class and social rank. Yet, as Agarwal demonstrates, young educated returnees do not passively submit to these expectations, but rather actively strive to assert positions of autonomy while at the same time integrating into the broader social contexts of Palauan society. As demonstrated through several case studies, and reflecting the situation of liminality described by Lee (this volume), within this context of social 'cognitive dissonance' young Palauan returnees must constantly refashion their sense of selfhood through careful and strategic processes of balancing and asserting agency. Such process not only entail conscious acts of self-fashioning, but also see them uniquely positioned to bring about positive social change at a local level.

Kirsten McGavin, in her chapter on diasporic Pacific Islanders living in Australia, emphasises and examines the crucial vitality of meanings and feelings of peles (place) in relation to 'home' and identity. Juxtaposing three richly detailed oral testimonies, McGavin argues for the importance of distinguishing between different forms of return mobility. In this way, her analysis adds an important dimension of agency and intentionality to the typology presented by Kempf (this volume, and see above), especially around what he terms 'reversal'. As she also recognises, the question of whether not return mobilities are conceptualised and performed as 'homecomings' is often a matter of choice and personal perspective, and as such becomes tied up with broader ambiguities surrounding personal identity and social acceptance. As her ethnographic findings demonstrate, and running counter to stereotypically positive meanings and values associated with notions of 'home', island visits and excursions that are specifically not conceptualised as 'homecomings'-such as touristic 
or business-related visits - are more likely to be experienced in a more positive way than those that are explicitly or primarily about 'visiting family back home'. Even so, as she also contends, the distinction between 'homecoming' and 'non-homecoming' is often ambiguous or unclear, which may itself give rise to situations of competing expectations between visitors and their family 'hosts'. As she concludes, these deeply situational, affective and relational qualities of return mobility are fundamental to the individual experience of peles (place) for diasporic Islanders.

Butt, Munro and Numbery also critically examine the gendered dimensions of homecoming, in their case as experienced and negotiated by women diagnosed and living with HIV in Tanah Papua, Indonesia. As they note, despite the strong association between mobility and HIV, especially as coupled with narratives of 'risk' in the case of female mobility, there have been surprisingly few studies of the moral expectations and emotional experiences that occur as women with HIV return home in search of treatment and support. This chapter presents a vital intervention of research findings and analysis aimed at filling this gap, and thereby contributing to the formulation of positive public health interventions in the region and beyond. As the authors demonstrate and examine through three contrasting ethnographic case studies, where relatively high infection rates are accompanied by contexts of deep stigmatisation, many such returns are fraught with unmet expectations on both sides. Indeed, in a context where the gendered expectation is that women give rather than receive care, far from finding the support they require, many women living with HIV are forced to avoid ostracism or abuse through strategies of secrecy and deception. As the authors argue, taking account of these social insights should be considered of critical importance to future public health planning and response around HIV. This is especially so considering the extent to which dominant responses in contexts such as Tanah Papua have, to date, been motivated by standardised international intervention strategies. In particular, those interventions need to tackle the 'hard truths' that lie beyond the optic of individual treatment adherence. This includes, as they forcefully demonstrate, that existing social contexts and discourses may and often do exacerbate rather than positively affect the situation of HIV-positive women.

Demonstrating a somewhat ironic reversal of hegemonic discourses and values involving urban opportunity and rural backwardness, Kolshus examines the prospects, promises and perils associated with travel to and from the small island of Mota and Vanuatu's urban centres Port Vila and 
Luganville. As he shows, for these islanders, choices around whether to leave or stay in either rural homeland or urban locations are informed by a complexly shifting combination of structural and ideational factors. With few educational or economic opportunities, and precariously positioned in terms of basic resources, the 'bright lights of town' have over the last several decades lured Mota islanders in search of new opportunities. As Kolshus demonstrates, however, faced with difficult and confronting situations of relative social alienation, increased economic hardship and the ontological uncertainties of sorcery, such excursions have continually been met with disappointment and peril. As a result, Mota islanders have come to cherish as a matter of pride and source of resilience the realisation that the world outside of their small island home has little to offer them. Even so, and despite this apparent reversal in orientation, the population continues to keep its options open, just as it has in the past. Indeed, as they recognise, the maintenance of footholds elsewhere is crucial given present and future ecological prospects associated with climate change.

The final chapter by Shu-Ling Yeh rounds out the examination of local agency in the context of return migration, in this case focusing on the homemaking practices of the indigenous Amis of Taiwan. As she explains, mobility among Austronesian-speaking indigenous populations in Taiwan are often described negatively at a national level, in terms of vagrancy, displacement or 'aimless drifting'. In stark contrast to these hegemonic descriptions, Yeh shows in great detail the high extent to which the members of one particular community constructed and imagine their village within the context of wider interactions with Taiwanese society. Here, the relationship between mobility and return mobility is a vital component to the generation and regeneration of community at a local level. Community activities such as church and house building, and annual or more sporadic ritual contexts are all dependent on the pooling of resources generated through dynamic exchanges within and across the local and translocal community. Underscoring the need to recognise the importance of home to contexts of migration and mobility seen otherwise in terms of negative precariousness or dependency, these relationships of exchange and development centred on home form an important source of pride, motivation for hard work and source of stability for those living outside of the village context.

The individual contributions to this volume each demonstrate the high methodological value of employing fine-grained ethnography to contexts of mobility, especially to understanding social relations, identity, and 
transforming meanings and values of home. While diverse in their core approaches, ranging from individual, life-story case studies, quantitative and survey-based approaches, and in-depth ethnographic description, each employs participant observation to reveal complexly shifting contexts, practices and experiences associated with return migration in and across the Pacific region. These range from largely domestic movements in which migrants are able to maintain relatively close ties with their homelands to wider scale international contexts of return mobility in which designations of home and away can become unsettlingly blurred, if not in some instances reversed. As such, the collection exemplifies the ongoing importance of ethnographic comparison to understanding processes of mobility in relation to home and return, and to showing how specific contexts of return mobility work to define individual and collective experience.

\section{References}

Banivanua-Mar, T 2007, Violence and colonial dialogue: the AustralianPacific indentured labor trade, University of Hawai'i Press, Honolulu.

Bertram, G 1999, 'The MIRAB model twelve years on', The Contemporary Pacific, vol. 11, no. 1, pp. 105-138.

Bertram, G \& Watters, RF 1985, 'The MIRAB economy in South Pacific microstates', Pacific Viewpoint, vol. 26, no. 3, pp. 497-519.

Castles, S \& Miller, MJ 2009, The age of migration: international population movements in the modern world, Macmillan, Basingstoke.

Curtain, R, Dornan, M, Doyle, J \& Howes, S 2016, Pacific Possible, Labour mobility: the ten billion dollar prize, World Bank Group and The Australian National University, Washington DC and Canberra.

D'Arcy, P 2006, The people of the sea: environment, identity and history in Oceania, University of Hawai'i Press, Honolulu.

Glick Schiller, N \& Salazar, NB 2013, 'Regimes of mobility across the globe', Journal of Ethnic and Migration Studies, vol. 39, no. 2, pp. 183-200. doi.org/10.1080/1369183X.2013.723253 
Gmelch, G 1980, 'Return migration', Annual Review of Anthropology, vol. 91, no. 1, pp. 135-159. doi.org/10.1146/annurev.an.09.100180. 001031

Graham, T 1995, Sugar slaves: The secret history of Australia's slave trade. Film Australia. Director/Co-Producer T. Graham. Producer P. Robbins.

Hau'ofa, E 1994, 'Our sea of islands', The Contemporary Pacific, vol. 6, no. 1 , pp. 148-161.

Howe, KR 2003, The quest for origins: who first discovered and settled New Zealand and the Pacific Islands?, University of Hawai'i Press, Honolulu.

Irwin, G 1992, The prehistoric exploration and colonization of the Pacific, Cambridge University Press, Cambridge. doi.org/10.1017/CBO 9780511518225

Jolly, M 2001, 'On the edge? Deserts, oceans, islands', The Contemporary Pacific, vol. 13, no. 2, pp. 417-466. doi.org/10.1353/cp.2001.0055

Jolly, M, Tryon, D \& Tcherkézoff, S 2009, Oceanic encounters: exchange, desire, violence, ANU E Press, Canberra.

Keck, V \& Schieder, D 2015, 'Contradictions and complexities—current perspectives on Pacific Islander mobilities', Anthropological Forum, vol. 25, no. 2, pp. 115-130. doi.org/10.1080/00664677.2014.999644

Lee, H \& Francis, ST (eds) 2009, Migration and transnationalism: Pacific perspectives, ANU E Press, Canberra.

Macpherson, C 1985, 'Public and private views of home: will Western Samoan migrants return?’ Pacific Viewpoint vol. 26, no. 1, pp. 242-262.

Macpherson, C 1994, 'Changing patterns of commitment to island homelands: a case study of Western Samoa', Pacific Studies, vol. 17, no. 3 , p. 83 .

Macpherson, C 1999, 'Will the "real" Samoans please stand up? Issues in diasporic Samoan identity', New Zealand Geographer, vol. 55, no. 2, pp. 50-59. doi.org/10.1111/j.1745-7939.1999.tb00542.x 
Macpherson, C 2004, 'From Pacific Islanders to Pacific people and beyond', in P Spoonley \& DG Pearson (eds), Tangata tangata: the changing ethnic contours of New Zealand, Cengage Learning Australia, Sydney, pp. 135-155.

Malinowski, B 1961 [1922], Argonauts of the Western Pacific: an account of native enterprise and adventure in the archipelagoes of Melanesian New Guinea, E.P. Dutton, New York.

Sheller, M \& Urry, J 2006, 'The new mobilities paradigm', Environment and Planning $A$, vol. 38, no. 2, pp. 207-226. doi.org/10.1068/a37268

Shineberg, D 1999, The people trade: Pacific island laborers and New Caledonia, 1865-1930, Pacific Islands Monograph Series no. 16, University of Hawai'i Press, Honolulu.

Sivasundaram, S 2005, Nature and the godly empire: science and evangelical mission in the Pacific, 1795-1850, Cambridge Social and Cultural Histories, vol. 7, Cambridge University Press, Cambridge.

Small, C 2011, Voyages: from Tongan villages to American suburbs, Cornell University Press, Ithaca.

Taylor, JP 2008, The other side: ways of being and place in Vanuatu, Pacific Islands Monograph Series, no. 22, University of Hawaii i Press, Honolulu. doi.org/10.21313/hawaii/9780824833022.001.0001

Thomas, N 2009, Entangled objects: Exchange, material culture, and colonialism in the Pacific. Harvard University Press, Cambridge, Massachusetts, and London, England.

Urry, J 2007, Mobilities, Polity Press, Cambridge.

Va'a, LF 2001, Saili matagi: Samoan migrants in Australia, Institute of Pacific Studies and Iunivesite Aoao o Samoa, Suva.

Van der Ryn, F 2012, 'Return migration to American Samoa', Pacific Studies, vol. 35, no. 1, pp. 252-279.

Ward, G 1997, 'Expanding worlds of Oceania: implications of migration', in K Sudo \& S Yoshida (eds), Population movement in the modern world I: contemporary migration in Oceania: diaspora and network, JCAS Symposium Series 3, The Japan Center for Area Studies, National Museum of Ethnology, Osaka, pp. 179-196. 
MOBILITIES OF RETURN

Willis, K 2010, 'Introduction: mobility, migration and development', International Development Planning Review, vol. 32, no. 3-4, pp. i-xiv. doi.org/10.3828/idpr.2010.15

Yngvesson, B \& Coutin, SB 2006, 'Backed by papers: undoing persons, histories, and return', American Ethnologist, vol. 33, no. 2, pp. 177-190. doi.org/10.1525/ae.2006.33.2.177 
This text is taken from Mobilities of Return: Pacific Perspectives, edited by John Taylor and Helen Lee, published 2017 by ANU Press, The Australian National University, Canberra, Australia.

dx.doi.org/10.22459/MR.12.2017.01 